\title{
Study of Lithium Disilicate Based Nano Glass Ceramics Containing P205.
}

\section{Anuradha Vilas Deshpande ( $\nabla$ avdeshpande@phy.vnit.ac.in )}

Visvesvaraya National Institute of Technology

\section{Peddy Satyanarayana}

Visvesvaraya National Institute of Technology

\section{Research Article}

Keywords: Lithium disilicate, Crystallinity, Microstructure, Microhardness, Fracture toughness, translucent glass ceramics

Posted Date: September 22nd, 2021

DOI: https://doi.org/10.21203/rs.3.rs-911589/v1

License: (c) (1) This work is licensed under a Creative Commons Attribution 4.0 International License. Read Full License

Version of Record: A version of this preprint was published at Silicon on February 14th, 2022. See the published version at https://doi.org/10.1007/s12633-021-01610-6. 


\title{
Study of Lithium disilicate based nano glass ceramics containing $\mathrm{P}_{2} \mathrm{O}_{5}$.
}

\author{
Authors and Affiliation \\ Anuradha Vilas Deshpande* and Peddy Satyanarayana \\ Department of Physics, Visvesvaraya National Institute of Technology, South Ambazari road, \\ Nagpur, Maharashtra, Pin- 440010, India \\ *Corresponding author Email: avdeshpande@phy.vnit.ac.in
}

\begin{abstract}
Multi component Lithium disilicate based glasses containing $\mathrm{P}_{2} \mathrm{O}_{5}$ have been synthesized by conventional melt quenching technique. The replacement of $\left(\mathrm{Li}_{2} \mathrm{O}+\mathrm{SiO}_{2}\right)$ by $\mathrm{P}_{2} \mathrm{O}_{5}$ and its nucleating effect has been discussed. Structural features of glasses were evaluated by DTA, FTIR and Raman spectroscopy. The glass samples have been converted into glass ceramics by following three stage heat treatment schedule. XRD, FESEM, HAADF imaging and EDX analysis has been carried out for glass ceramics. Vickers microhardness and Vickers indentation fracture toughness of all the glass ceramics have been measured. UV-Visible spectroscopy study has been carried out for glass ceramics to investigate the optical properties. The glass ceramic with $1.5 \mathrm{~mol} \% \mathrm{P}_{2} \mathrm{O}_{5}$ has highest transmittance. Glass ceramics with $\mathrm{P}_{2} \mathrm{O}_{5} \geq 1$ mol \% having $\mathrm{Li}_{2} \mathrm{Si}_{2} \mathrm{O}_{5}$ as main phase exhibit high Vickers microhardness $\left(\mathrm{H}_{\mathrm{v}}\right)$ about 6.71-6.82 $\mathrm{GPa}$ which is suitable for dental and armor applications.
\end{abstract}

Keywords: Lithium disilicate, Crystallinity, Microstructure, Microhardness, Fracture toughness and translucent glass ceramics

\section{Introduction}

Lithium disilicate glass-ceramics have been attracting attention of mankind since decades because of their excellent mechanical and translucent properties. Addition of nucleating agents, fluxing agents and colorants has been studied in lithium disilicate system earlier. Fine grain micro structure in these glass ceramics has been reported to improve mechanical properties [1]. Generally surface crystallization dominates in pure Lithium disilicate glass ceramics which results in growth of larger crystals hampering the mechanical properties. Hence, it is necessary to add nucleating agents to promote uniform volume crystallization so that the optimized 
mechanical properties can be achieved [2]. Moreover suitable heat treatment is essential to induce crystalline part in glass matrix, as a result the mechanical properties can be further improved. $\mathrm{P}_{2} \mathrm{O}_{5}$ has been suggested to be a well known nucleating agent for Lithium disilicate glass systems. Addition of $\mathrm{P}_{2} \mathrm{O}_{5}$ in Lithium disilicate system can induce amorphous phase separation through the precipitation of $\mathrm{Li}_{3} \mathrm{PO}_{4}$ (LP) which leads to formation of stable $\mathrm{Li}_{2} \mathrm{Si}_{2} \mathrm{O}_{5}$ $\left(\mathrm{LS}_{2}\right)$ phase [3]. Kun Yuan et al. [4] reported that the sintering time affects the flexural strength of Lithium disilicate based glass ceramics. W. Höland et al. [5] reported that bulk crystallization can be controlled by addition of $\mathrm{P}_{2} \mathrm{O}_{5}$. Yang Bai et al. [6] reported that two stage heat treatment is suitable to grow lithium disilicate phase and smaller dimensional crystals can be obtained when the samples are heat treated at temperature lower than the second crystallization peak temperature. $\mathrm{SiO}_{2}-\mathrm{Li}_{2} \mathrm{O}-\mathrm{K}_{2} \mathrm{O}-\mathrm{ZnO}-\mathrm{P}_{2} \mathrm{O}_{5}$ glass ceramic system with $\mathrm{P}_{2} \mathrm{O}_{5}$ content $<0.5 \mathrm{~mol} \%$ possesses surface crystallization and glass ceramics with $\mathrm{P}_{2} \mathrm{O}_{5}$ content between 1-2.5 mol \% have elongated rod shaped crystals. Segre Borone et al. [7] quantitatively reported that precipitation of $\beta$-cristobalite at the interface of $\mathrm{Li}_{2} \mathrm{SiO}_{3}(\mathrm{LS}) /$ amorphous matrix promotes $\mathrm{LS}_{2}$ phase formation. Along with the mechanical properties, transparency is another important property to be improved for lithium disilicate glass ceramics. Glass ceramics with higher transparency can be used in several applications such as bomb disposal works, ceramic cook tops and bullet proof vests. Transparency can be achieved if the size of crystals is in nano meter range. $\mathrm{P}_{2} \mathrm{O}_{5}$ is one of the promising nucleating agents for reducing the crystal size and promoting bulk crystallization in Lithium disilicate glass ceramic system. Moreover, presence of small crystals improves mechanical properties of glass ceramics. Fu wang et al. [8] have studied the flexural strength, microstructure and contrast ratio of Lithium disilicate glass ceramics containing $\mathrm{P}_{2} \mathrm{O}_{5}$ and reported that the glass ceramic with 1 mol $\% \mathrm{P}_{2} \mathrm{O}_{5}$ showed elongated rod like $\mathrm{Li}_{2} \mathrm{Si}_{2} \mathrm{O}_{5}$ crystals and exhibited highest flexural strength. Even though Lithium disilicate glass ceramics containing $\mathrm{P}_{2} \mathrm{O}_{5}$ have been extensively studied the correlation between crystallinity, micro structure, microhardness, fracture toughness and optical properties of these glass ceramics has not been reported earlier.

Thus, the present work is aimed at the study of effect of $\mathrm{P}_{2} \mathrm{O}_{5}$ addition on the crystallization kinetics, microstructure, Vickers microhardness $\left(\mathrm{H}_{\mathrm{v}}\right)$, Vickers indentation fracture toughness $\left(\mathrm{K}_{\mathrm{IC}}\right)$ and optical properties of lithium disilicate system $\left(\mathrm{SiO}_{2}-\mathrm{Li}_{2} \mathrm{O}-\mathrm{ZrO}_{2}-\mathrm{K}_{2} \mathrm{O}-\mathrm{Al}_{2} \mathrm{O}_{3}-\right.$ 
$\mathrm{MgO}-\mathrm{CaO}-\mathrm{CeO}_{2}$ ) synthesized by melt quenching technique and correlation between the microstructure, physical and optical properties.

\section{Materials and methods}

Lithium disilicate glass system $\left(\mathrm{SiO}_{2}-\mathrm{Li}_{2} \mathrm{O}-\mathrm{ZrO}_{2}-\mathrm{K}_{2} \mathrm{O}-\mathrm{Al}_{2} \mathrm{O}_{3}-\mathrm{MgO}-\mathrm{CaO}-\mathrm{CeO}_{2}\right)$ with addition of $0,0.5,1,1.5$ and $2 \mathrm{~mol} \% \mathrm{P}_{2} \mathrm{O}_{5}$ has been synthesized by conventional melt quenching technique. $\mathrm{P}_{2} \mathrm{O}_{5}$ has been added at the cost of $\mathrm{SiO}_{2}$ and $\mathrm{Li}_{2} \mathrm{O}$ by keeping their molar ratio $~ 2.4$. Standard laboratory analytic grade $\mathrm{SiO}_{2}$ (Sigma-aldrich>99.9\%), $\mathrm{Li}_{2} \mathrm{CO}_{3}\left(\right.$ Merck>99\%), $\mathrm{ZrO}_{2}$ (Aldrich>99\%), $\mathrm{K}_{2} \mathrm{CO}_{3}$ (Merck>99\%), $\mathrm{Al}_{2} \mathrm{O}_{3}$ (Merck>98\%), $\mathrm{MgO}$ (Merck>97\%), $\mathrm{CaCO}_{3}$ (Merck>98.5\%), $\mathrm{CeO}_{2}\left(\right.$ Aldrich>99.95\%) and $\mathrm{NH}_{4} \mathrm{H}_{2} \mathrm{PO}_{4}($ Merck>98.5\%) powders were used as the raw materials to synthesize glasses. The compositions and nomenclature of synthesized glasses have been given in Table 1 . The batches taken in molar ratio have been melted at $1450^{\circ} \mathrm{C}$ in platinum crucible for $2 \mathrm{~h}$ and quenched into preheated aluminium moulds of $4 \times 5 \times 10 \mathrm{~mm}$, then instantly transferred into annealing furnace in order to remove internal stresses. The glasses have been ground into cuboids of $2 \times 5 \times 10 \mathrm{~mm}$ with the help of diamond precision saw.

Crystallization kinetic parameters such as activation energies of crystallization and Avrami parameters have been determined for all the glasses using non isothermal method. For differential thermal analysis (DTA) purpose, glasses were ground into powder of 100-200 $\mu \mathrm{m}$ granules. The DTA has been carried out for all the glasses using simultaneous DTA-TG (SHIMADZU). The DTA runs have been carried out from room temperature to $1000{ }^{\circ} \mathrm{C}$ under flowing nitrogen atmosphere at different heating rates $\left(\alpha=5,10,15\right.$ and $\left.20^{0} \mathrm{~K} \cdot \mathrm{min}^{-1}\right)$. All the glasses have been converted into glass ceramics by following three stage heat treatment schedules. $\mathrm{T}_{\mathrm{g}}, \mathrm{T}_{\mathrm{C} 1 \mathrm{onset}}$, and $\mathrm{T}_{\mathrm{C} 2 \mathrm{onset}}$ observed from the DTA curves corresponding to the heating rate of $10 \mathrm{~K} / \mathrm{min}$ were chosen as holding temperatures for heat treatment of glass samples. The nomenclature and heat treatment schedule is given in Table 2.

Table 1. Nomenclature and chemical compositions of glasses in mol \%.

\begin{tabular}{llllll}
\hline Composition & G1 & G2 & G3 & G4 & G5 \\
\hline $\mathbf{S i O}_{2}$ & 66.70 & 66.4 & 66 & 65.5 & 65.2 \\
$\mathbf{L i}_{2} \mathbf{O}$ & 27.70 & 27.5 & 27.4 & 27.3 & 27.2 \\
$\mathrm{Al}_{2} \mathbf{O}_{3}$ & 1.8 & 1.8 & 1.8 & 1.8 & 1.8 \\
$\mathbf{Z r O}_{2}$ & 1.4 & 1.4 & 1.4 & 1.4 & 1.4 \\
$\mathbf{K}_{2} \mathbf{O}$ & 1.8 & 1.8 & 1.8 & 1.8 & 1.8 \\
\hline
\end{tabular}




\begin{tabular}{llllll}
\hline $\mathrm{P}_{2} \mathrm{O}_{5}$ & 0 & 0.5 & 1 & 1.5 & 2 \\
$\mathrm{MgO}$ & 0.2 & 0.2 & 0.2 & 0.2 & 0.2 \\
$\mathrm{CaO}$ & 0.2 & 0.2 & 0.2 & 0.2 & 0.2 \\
$\mathrm{CeO}_{2}$ & 0.2 & 0.2 & 0.2 & 0.2 & 0.2 \\
\hline
\end{tabular}

Table 2. Nomenclature and heat treatment schedule of glass ceramics.

\begin{tabular}{ccccc}
\hline $\mathbf{P}_{2} \mathbf{O}_{5} \mathbf{~ m o l ~ \%}$ & $\begin{array}{c}\text { Glass ceramic } \\
\text { name }\end{array}$ & $\mathbf{T}_{\mathbf{g}}\left({ }^{\circ} \mathbf{C}\right) /$ Dwell time (min) & $\begin{array}{c}\mathbf{T}_{\mathbf{C} 10 n}\left({ }^{\circ} \mathbf{C}\right) / \text { Dwell time } \\
(\mathbf{m i n})\end{array}$ & $\begin{array}{c}\mathbf{T}_{\mathbf{C} 20 n}\left({ }^{\circ} \mathbf{C}\right) / \mathbf{D w e l l ~ t i m e ~} \\
(\mathbf{m i n})\end{array}$ \\
\hline $\mathbf{0}$ & GC-1 & $474 / 90$ & $622 / 90$ & $859 / 60$ \\
$\mathbf{0 . 5}$ & GC-2 & $476 / 90$ & $636 / 90$ & $838 / 60$ \\
$\mathbf{1}$ & GC-3 & $479 / 90$ & $632 / 90$ & $819 / 60$ \\
$\mathbf{1 . 5}$ & GC-4 & $482 / 90$ & $574 / 90$ & $780 / 60$ \\
$\mathbf{2}$ & GC-5 & $483 / 90$ & $589 / 90$ & $787 / 60$ \\
\hline
\end{tabular}

Crystalline phases have been identified by using X-ray diffraction technique (XRD, Rigaku, Japan). The analysis has been done using $\mathrm{Cu}-\mathrm{K} \alpha$ radiation with a step size of $0.01^{\circ}$ and $2 \theta$ ranging from $10^{\circ}$ to $60^{\circ}$. Crystallinity of lithium disilicate glass ceramics has been determined using relation (1) [9].

$$
\% \text { Crystallinity }=\frac{A_{c}}{A_{c}+A_{a}} \times 100 \%
$$

Where, $A_{c}$ and $A_{a}$ are the area under the peaks representing total crystalline and the amorphous phase respectively.

All the glass ceramics in the shape of cuboids were wet ground with silicon carbide emery papers (grit size ranging from 320 to 2000) and then finally were polished with fine grade alumina suspension $(0.3 \mu \mathrm{m})$ on velvet cloth. Each sample was indented with ten indentations with the help of Vickers diamond pyramid and knoop indenters (Microhardness tester model: F. AUTO-II, Metatech, India) in order to measure microhardness. A load of $1 \mathrm{~kg}$ for 10 seconds has been used for all the glass ceramics.

The Vickers hardness, knoop hardness, Elastic modulus and Fracture toughness (KIC) were calculated by using the relations (2), (3), 4) and (5) respectively [1,10,11].

$$
\begin{aligned}
& H_{v}=1.8544\left(\frac{P}{d 2}\right)\left(\mathrm{Kg} \mathrm{mm}^{-2}\right) \\
& H_{k}=14.229\left(\frac{P}{a 2}\right)\left(\mathrm{Kg} \mathrm{m}^{-2}\right) \\
& E=\frac{0.45 H_{k}}{\left(0.1406-\frac{b}{a}\right)}(G P a)
\end{aligned}
$$




$$
K_{I C}=0.016 \sqrt{\frac{E}{H_{v}}}\left(\frac{P}{C^{1.5}}\right)(M P a \sqrt{m})
$$

Where, $H_{v}$-Vickers hardness, $H_{k}$-knoop hardness, $P$-applied load, $d$-average diagonal length of vicker's indentation mark, ' $b$ ' and ' $a$ ' are lengths of minor and major diagonals of knoop indentation mark respectively, $C$-length of the crack from indentation center to end of the crack and $E$ - modulus of elasticity.

The FTIR studies have been carried out at room temperature for all the glasses using FTIR spectrometer (SHIMADZU IR Affinity-1) in the range of 500-1500 $\mathrm{cm}^{-1}$. For FTIR study the glasses have been ground into fine powder. Raman spectra were recorded on the polished solid glasses with Raman spectrometer (NOST.) using a He-Ne laser (532 nm). The measurements were performed from $500-1200 \mathrm{~cm}^{-1}$ at room temperature with $10 \mathrm{~mW}$ incident laser power. 100x objective lens was used to focus on the polished surface of the solid glass samples.

The polished glass ceramics have been etched with 5 vol \% Hydrofluoric acid for 3 min. Microstructure of all the etched glass ceramics have been observed using field emission scanning electron microscope (FESEM, Zeiss ultra 55). High angle annular dark field (HAADF) analysis has been carried out for the glass ceramics containing 1.5 mol \% $\mathrm{P}_{2} \mathrm{O}_{5}$ using Scanning tunneling electron microscopy (STEM) technique (TALOS F200S G2). The elements present in the glass ceramic containing $1.5 \mathrm{~mol} \% \mathrm{P}_{2} \mathrm{O}_{5}$ have been confirmed by Energy dispersive X-Ray spectroscopy (EDX). For this purpose the glass ceramic has been gently ground using white AGATE mortar and pestle. Then the glass ceramic powder has been dispersed in pure ethyl alchohol and kept for ultrasonic bath for few minutes. A carbon coated 200-mesh TEM copper grid was placed in the suspension and then remained until the ethyl alchohol gets evaporated leaving the glass ceramic particles on the copper grid before STEM analysis.

UV-Visible transmittance spectroscopy has been carried out for all the glass ceramics by UV-Visible spectrophotometer (AvaSpec-version 2.2) in the range from 300-800 nm. Fine polished $2 \times 5 \times 10 \mathrm{~mm}$ samples have been used to perform the UV-Visible spectroscopy.

\section{Results and discussion}

\subsection{Differential thermal analysis (DTA) and non isothermal crystallization kinetics}

Fig.1 (a) shows DTA plots for all glasses at 10K/min. Fig. 1(b) shows the DTA plots of glass containing $1 \mathrm{~mol} \% \mathrm{P}_{2} \mathrm{O}_{5}$ at 5-20K/min. All the curves show an endothermic peak 
corresponding to glass transition temperature $\left(\mathrm{T}_{\mathrm{g}}\right)$ and two exothermic peaks $\mathrm{T}_{\mathrm{P} 1}$ and $\mathrm{T}_{\mathrm{P} 2}$. The peak $\mathrm{T}_{\mathrm{P} 1}$ at lower temperature corresponds to LS phase and the peak $\mathrm{T}_{\mathrm{P} 2}$ at higher temperature corresponds to $\mathrm{LS}_{2}$ phase [12]. $\mathrm{T}_{\mathrm{g}}, \mathrm{T}_{\mathrm{P} 1}$ and $\mathrm{T}_{\mathrm{P} 2}$ for all the glasses have been given in the Table 3 . The glasses with $\mathrm{P}_{2} \mathrm{O}_{5} \leq 1 \mathrm{~mol} \%$ exhibit broad crystallization peaks indicating the larger full width at half maximum. The glasses with $\mathrm{P}_{2} \mathrm{O}_{5}>1$ mol \% exhibit sharp crystallization peaks indicating smaller full width at half maximum. It is reported earlier that larger full width at half maximum of DTA peaks results in smaller Avrami parameter (n) which indicates surface crystallization while smaller full width at half maximum gives larger Avarami parameter which indicates volume crystallization [13]. We assume that our glass without $\mathrm{P}_{2} \mathrm{O}_{5}$ content exhibits surface crystallization. With the increase in mol $\% \mathrm{P}_{2} \mathrm{O}_{5}$, the $\mathrm{T}_{\mathrm{g}}$ has been observed to increase. $\mathrm{T}_{\mathrm{P} 1}$ has been observed to increase with increasing $\mathrm{P}_{2} \mathrm{O}_{5}$ up to $1 \mathrm{~mol} \%$ while for the glasses containing $\mathrm{P}_{2} \mathrm{O}_{5}>1 \mathrm{~mol} \%$ it has been observed to decrease as shown in Fig.1 (a). $\mathrm{T}_{\mathrm{P} 2}$ has been observed to decrease continuously with the addition of $\mathrm{P}_{2} \mathrm{O}_{5}$.
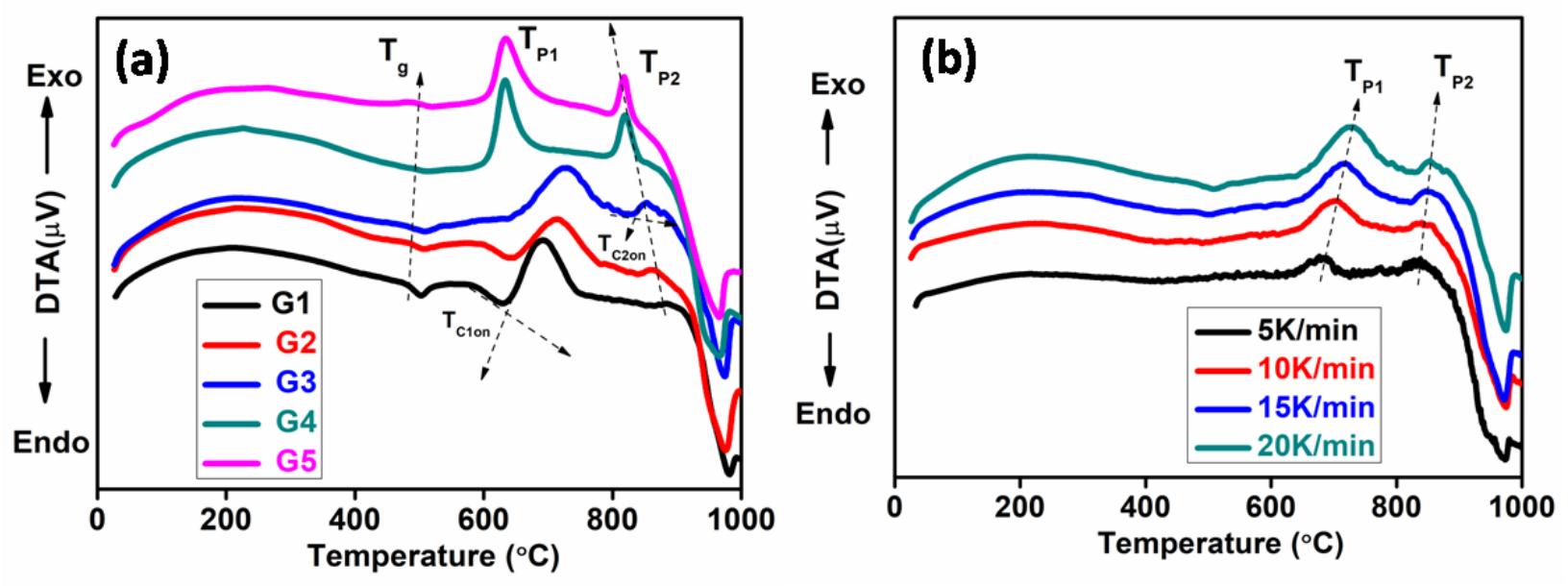

Fig.1. DTA plots for (a) glasses containing 0-2 mol \% $\mathrm{P}_{2} \mathrm{O}_{5}$ at $10 \mathrm{~K} / \mathrm{min}$ and (b) glass containing $1 \mathrm{~mol} \%$ $\mathrm{P}_{2} \mathrm{O}_{5}$ at $5-20 \mathrm{~K} / \mathrm{min}$.

Kissinger method has been used to calculate the activation energies of crystallization corresponding to the exothermic peaks as given by the relation (6) $[12,14]$ :

$$
\ln \frac{T_{P}{ }^{2}}{\alpha}=\frac{E_{C}}{R T_{P}}+\ln \frac{E_{C}}{R v}
$$

$T_{P}, \alpha, \mathrm{R}$ and $v$ are the peak temperature observed, heating rate used in DTA, universal gas constant and frequency factor respectively. The expression (6) yields a straight line and the activation 
energy for crystallization $\mathrm{E}_{C}$ can be determined from the slope of $\ln \left[T_{P}{ }^{2} / \alpha\right]$ versus $T_{P}{ }^{-1}$. Once the $E_{C}$ is known, the Avrami parameter ' $n$ ' can be calculated using the Augis and Bennett relation (7) [13] ;

$$
n=\frac{2.5}{\Delta T} \frac{R T_{P}{ }^{2}}{E_{C}}
$$

Where ' $\Delta T$ ' is the full width half maximum intensity of the exothermic peak obtained from DTA.

The crystallization peak temperature shifts to higher values as the heating rate is increased as shown in Fig. 1 (b). Similar variation is observed for all the glasses. This may be due to the fact that faster heating rate provides shorter duration of time for nucleation as a result nucleation starts at high temperature at which the melt is at lower viscosity [15]. Using relation (6), the plots have been drawn between $\ln \left(T_{p}{ }^{2} / \alpha\right)$ and 10000/T as shown in Fig. $2(a, b)$. The variation of activation energies with mol \% $\mathrm{P}_{2} \mathrm{O}_{5}$ corresponding to the first and second exothermic peaks for all the glasses has been shown in Fig.2 $(c, d)$ respectively. The decrease in activation energy corresponding to first crystallization temperature $\left(\mathrm{E}_{\mathrm{C} 1}\right)$ observed from Fig. 2(c) may be due to the heterogeneous nucleation effect of $\mathrm{P}_{2} \mathrm{O}_{5}$. Addition of $\mathrm{P}_{2} \mathrm{O}_{5}$ causes more number of nucleation sites and thus the crystallization starts at lower temperature which has been predominantly observed for glasses containing $\mathrm{P}_{2} \mathrm{O}_{5} \geq 1.5 \mathrm{~mol} \%$. The reason for increase in activation energy corresponding to second crystallization temperature $\left(\mathrm{E}_{\mathrm{C} 2}\right)$ is further to be investigated. The activation energies along with goodness of fit $\mathrm{R}^{2}$ and Avrami parameters for all glasses have been given in Table 4. With the addition of $\mathrm{P}_{2} \mathrm{O}_{5}$ the Avrami parameter corresponding to first crystallization temperature has been observed to increase from 1.15 to 2.48 while for second crystallization temperature it varies in between 1.84 to 3.02 as shown in Fig. 3(a) and 3(b). From the earlier reports $n \approx 1$ indicates surface nucleation and growth towards inside, $\mathrm{n} \approx 2$ volume nucleation and one dimensional growth and $\mathrm{n} \approx 3$ indicates volume nucleation and two dimensional growth $[12,16]$. This indicates that LS phase forms through surface crystallization and $\mathrm{LS}_{2}$ phase forms through volume crystallization. The surface crystallization has been observed for GC-1 using cross sectional SEM (Provided as supplementary file S1). The increment in Avrami parameter for the LS phase indicates that $\mathrm{P}_{2} \mathrm{O}_{5}$ addition alters the nucleation process and causes heterogeneous volume nucleation. 

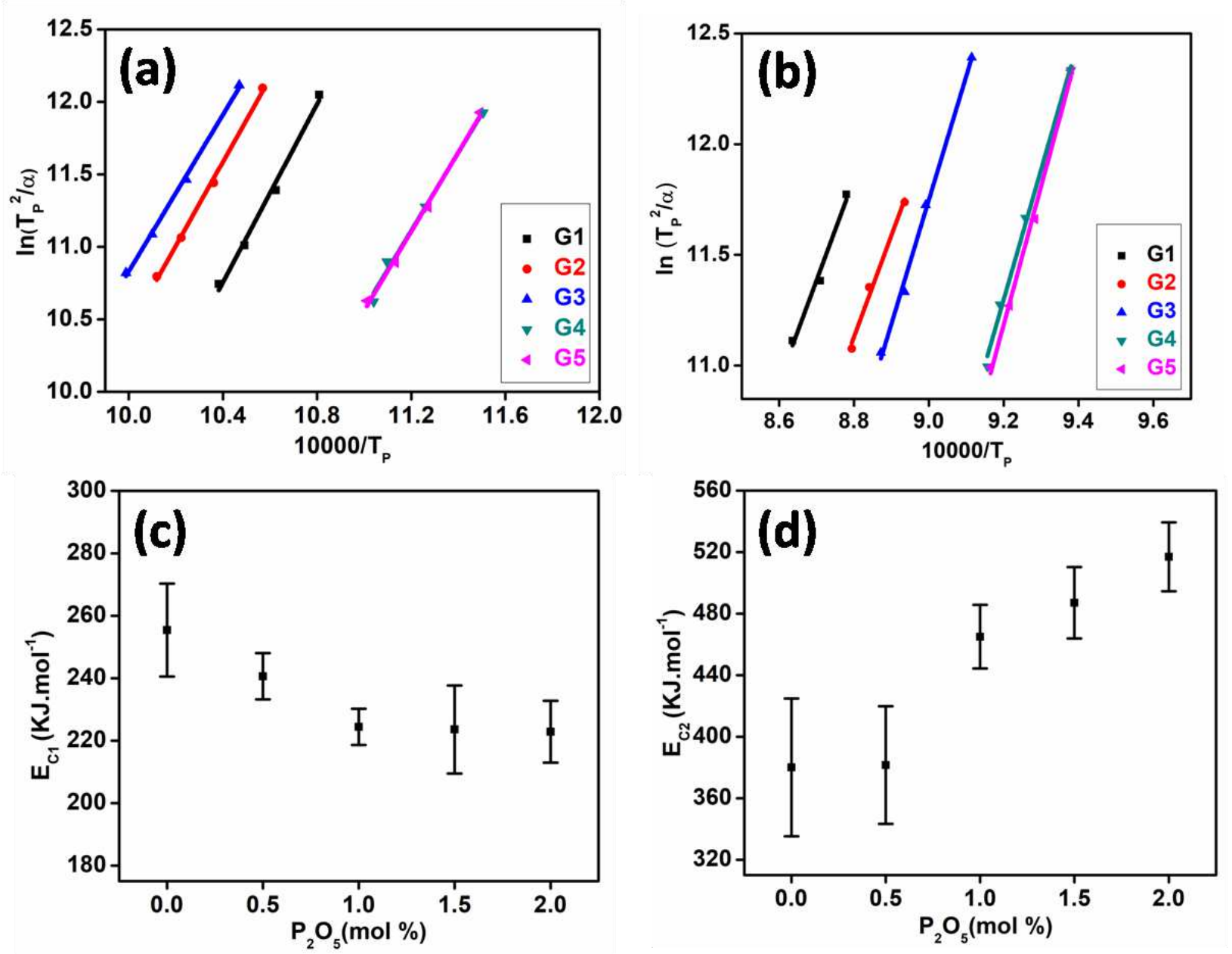

Fig 2. (a,b) Plots between $\ln \left(T_{P}^{2} / \alpha\right)$ and $10000 / T_{P}$ and Fig. $2(\mathrm{c}, \mathrm{d})$ Variation of activation energies $\mathrm{E}_{\mathrm{C} 1}$ and $\mathrm{E}_{\mathrm{C} 2}$ with mol \% $\mathrm{P}_{2} \mathrm{O}_{5}$ respectively.
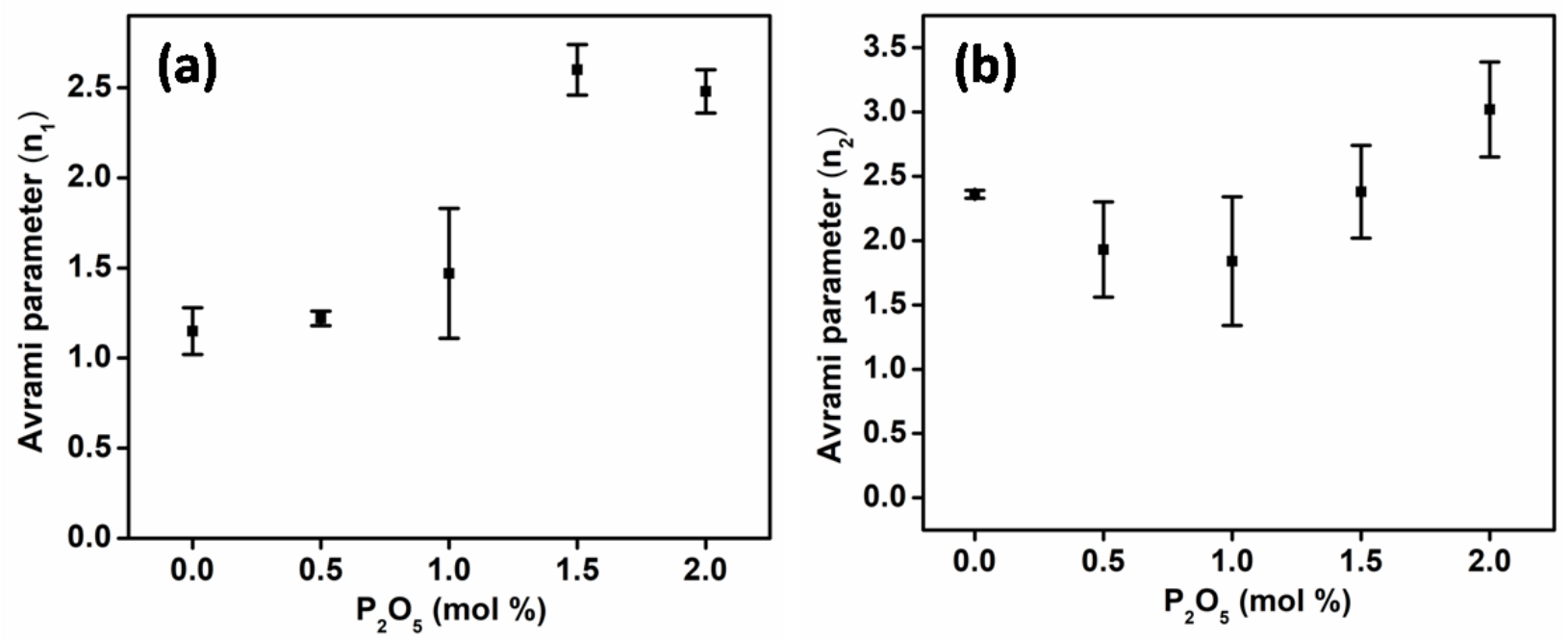
Fig. 3 Avrami parameter for all glasses corresponding to (a) first exothermic peak and (b) second exothermic peak respectively.

Table 3. $\mathrm{T}_{\mathrm{g}}, \mathrm{T}_{\mathrm{C} 1 \mathrm{on}}, \mathrm{T}_{\mathrm{P} 1}, \mathrm{~T}_{\mathrm{C} 2 \mathrm{on}}, \mathrm{T}_{\mathrm{P} 2}$ values for all glasses at different heating rates

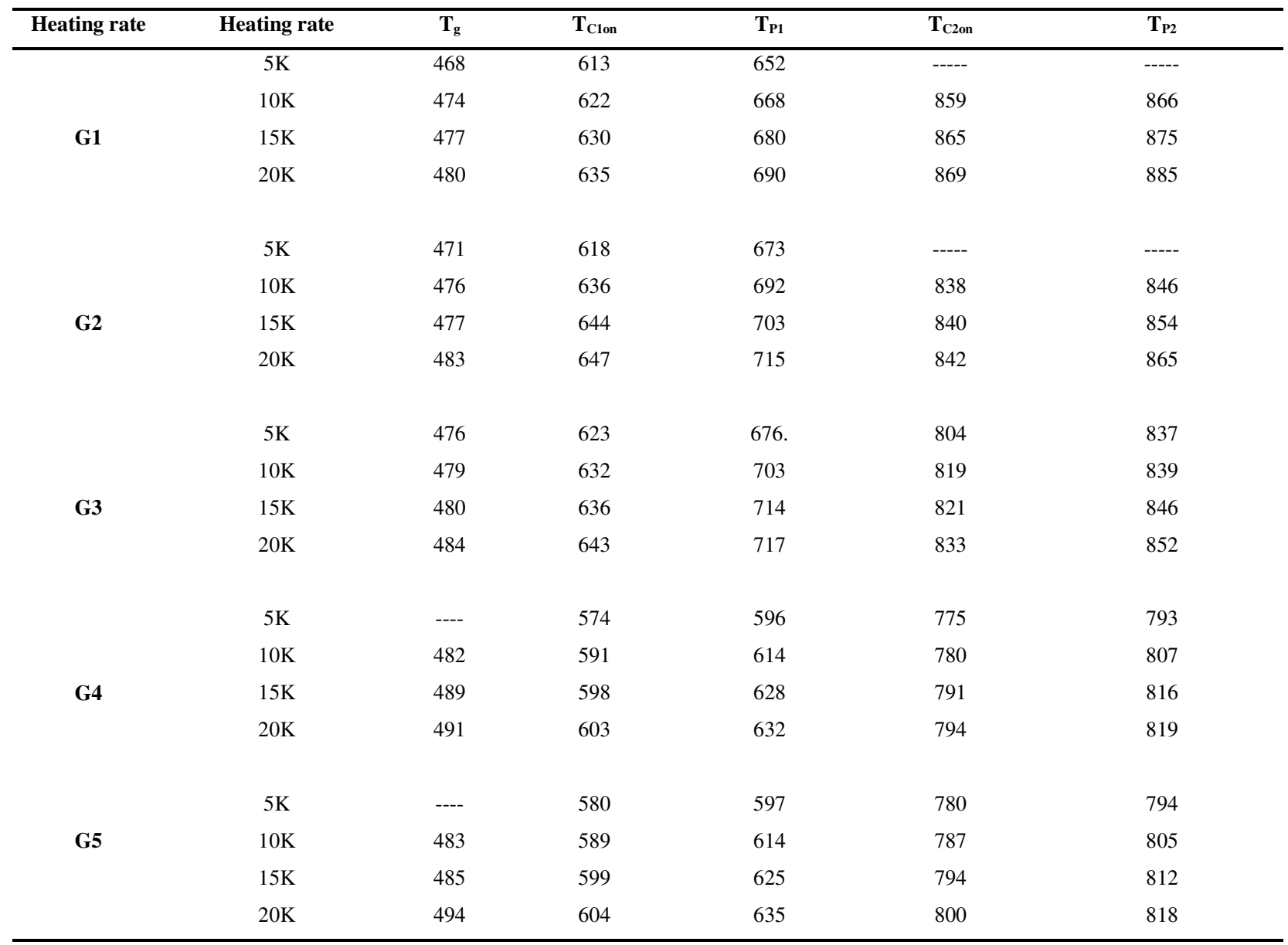

Table 4. Activation energies and Avrami parameters for all glasses.

\begin{tabular}{|c|c|c|c|c|c|c|}
\hline \multirow[b]{2}{*}{ Glass } & \multicolumn{4}{|c|}{ Kissinger method $\left(\right.$ KJ.mol$\left.^{-1}\right)$} & \multicolumn{2}{|c|}{ Augis and Bennet method } \\
\hline & $\overline{E_{\mathrm{C} 1}}$ & Goodness of fit $\mathrm{R}^{2}$ & $\overline{E_{\mathrm{C} 2}}$ & Goodness of fit $\mathrm{R}^{2}$ & $\left\langle n_{l}\right\rangle \pm$ S.D. & $\left\langle n_{1}\right\rangle \pm$ S.D. \\
\hline G1 & $255.40 \pm 14.9$ & 0.989 & $380 \pm 44.49$ & 0.984 & $1.15 \pm 0.13$ & $2.36 \pm 0.03$ \\
\hline G2 & $240.6 \pm 7.8$ & 0.996 & $381.1 \pm 38.2$ & 0.972 & $1.22 \pm 0.04$ & $1.93 \pm 0.37$ \\
\hline G3 & $224.4 \pm 5.8$ & 0.997 & $465 \pm 20.7$ & 0.993 & $1.47 \pm 0.36$ & $1.84 \pm 0.5$ \\
\hline G4 & $223.56 \pm 14.1$ & 0.987 & $487 \pm 23.2$ & 0.993 & $2.60 \pm 0.14$ & $2.38 \pm 0.36$ \\
\hline G5 & $222.86 \pm 9.9$ & 0.974 & $517 \pm 22.4$ & 0.994 & $2.48 \pm 0.12$ & $3.02 \pm 0.37$ \\
\hline
\end{tabular}

$<>$ - Average, S. D. - Standard deviation. 


\subsection{XRD}

XRD patterns of all glass ceramics are shown in Fig. 4. The Fig. 4 shows that glass ceramic with $\mathrm{P}_{2} \mathrm{O}_{5} \leq 0.5 \mathrm{~mol} \%$ has mainly LS phase (JCPDS no. 74-2145) along with minor LS phase (JCPDS no.82-2396), Quartz (JCPDS no. 07-0346) and cristobalite (JCPDS no. 04-0359) phases. In the glass ceramics with $\mathrm{P}_{2} \mathrm{O}_{5} \leq 0.5 \mathrm{~mol} \%$, LS crystalline phase has been formed due to the reaction between $\mathrm{Li}_{2} \mathrm{O}$ and $\mathrm{SiO}_{2}$ in the glassy matrix (reaction 8). It can be observed from the Fig. 4 that with the addition of $\mathrm{P}_{2} \mathrm{O}_{5} \geq 1 \mathrm{~mol} \% \mathrm{LS}_{2}$ phase has been developed along with minor LP $\left(\mathrm{Li}_{3} \mathrm{PO}_{4}\right)$ ( JCPDS no 25-1030) phase while LS phase has not been observed.

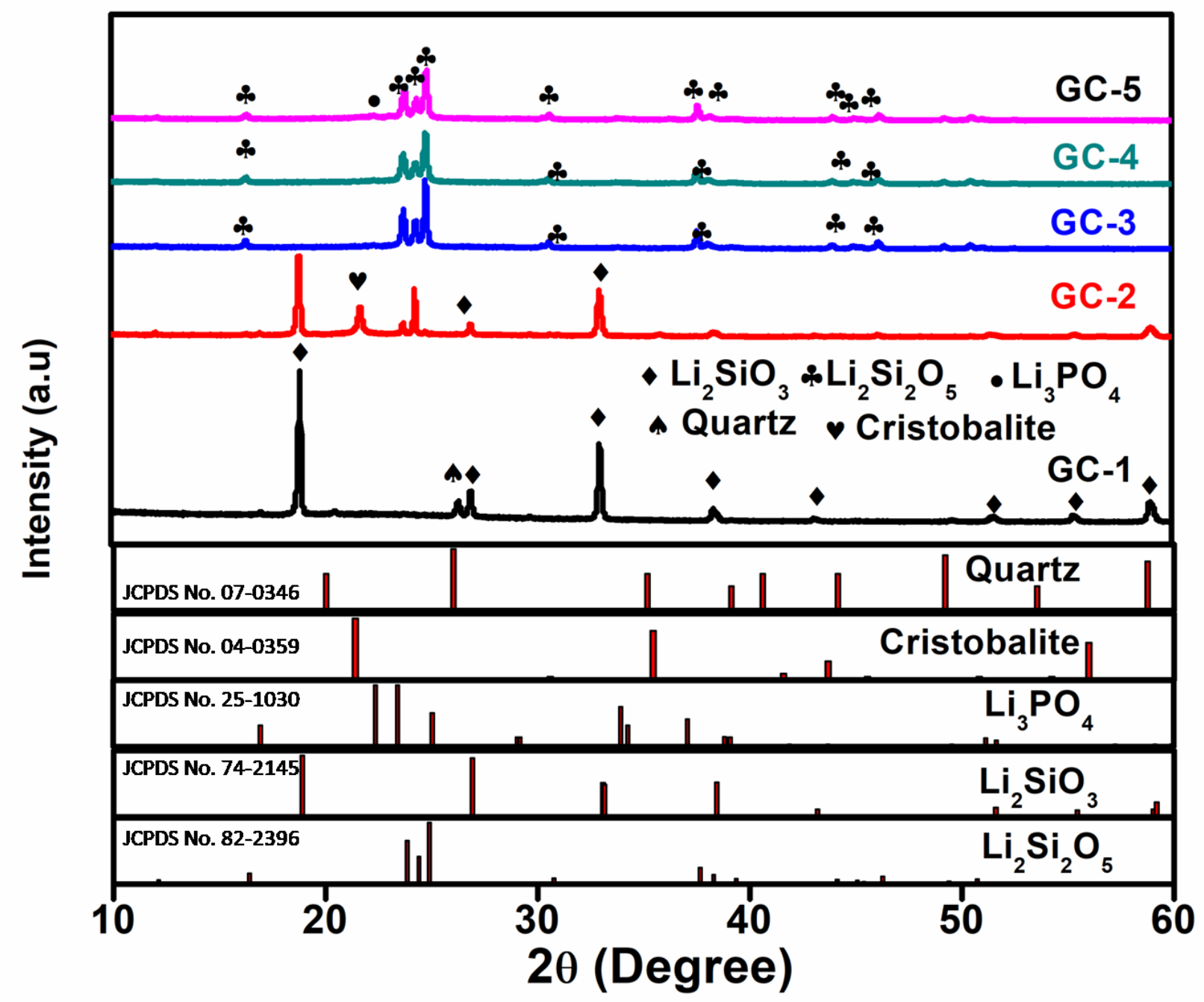

Fig. 4. XRD patterns of glass ceramics containing 0-2 mol \% $\mathrm{P}_{2} \mathrm{O}_{5}$ respectively. 
The $\mathrm{LS}_{2}$ phase formation in the glass ceramics containing $\mathrm{P}_{2} \mathrm{O}_{5} \geq 1 \mathrm{~mol} \%$ may occur in following way. The high field strength $\mathrm{P}^{5+}$ ions attract the $\mathrm{O}^{2-}$ ions from the glass matrix leading to the formation of $\mathrm{PO}_{4}{ }^{3-}$ and the $\mathrm{Li}^{+}$ions are attracted towards the phosphates in order to balance their negative charge forming the amorphous LP phase (reactions 9 and 10) [17] . Pauline Glatz et al. [18] earlier did the ${ }^{31} \mathrm{P}$ MAS-NMR studies on $\mathrm{LS}_{2}$ based glasses and reported that the Phosphate units are surrounded by $\mathrm{Li}+$ cations which supports our analogy.

$$
\begin{gathered}
\mathrm{Li}_{2} \mathrm{O}_{\text {(amorphous) }}+\mathrm{SiO}_{2} \text { (amorphous) } \rightarrow \mathrm{Li}_{2} \mathrm{SiO}_{3} \text { (crystal) } \\
\left(\mathrm{Si}-\mathrm{O}^{\cdots} \mathrm{Li}^{+}\right)_{\text {(glass) }}+\mathrm{P}_{2} \mathrm{O}_{5} \rightarrow 3(\mathrm{Si}-\mathrm{O}-\mathrm{Si})_{\text {(glass) }}+2 \mathrm{Li}_{3} \mathrm{PO}_{4} \text { (glass) } \\
\mathrm{P}_{2} \mathrm{O}_{5} \text { (glass) }+3 \mathrm{Li}_{2} \mathrm{O}_{\text {(glass) }} \rightarrow 2 \mathrm{Li}_{3} \mathrm{PO}_{4} \text { (glass) }
\end{gathered}
$$

These amorphous LP species may serve as nucleation sites for the formation of $\mathrm{LS}_{2}$ phase according to the reaction (11)[17].

$$
\mathrm{Li}_{2} \mathrm{O}_{\text {(amorphous) }}+2 \mathrm{SiO}_{2} \text { (amorphous) } \rightarrow \mathrm{Li}_{2} \mathrm{Si}_{2} \mathrm{O}_{5} \text { (crystal) }
$$

Christine Bischoff et al. [19] have previously reported the NMR and XRD studies of multi component Lithium disilicate based glass ceramics which revealed that phosphate species exist in highly disordered state and the heterogeneous nucleation of $\mathrm{LS}_{2}$ phase takes place at the compositional gradient of amorphous LP and the glass matrix. This analogy supports the formation of $\mathrm{LS}_{2}$ phase for the glass ceramics containing $\mathrm{P}_{2} \mathrm{O}_{5} \geq 1 \mathrm{~mol} \%$ in this study. Thus, the glass ceramics with $\mathrm{P}_{2} \mathrm{O}_{5} \geq 1 \mathrm{~mol} \%$ exhibit heterogeneous nucleation and crystal growth of $\mathrm{LS}_{2}$ phase.

Moreover, the amorphous LP is expected be converted into crystalline LP at higher temperature near $\mathrm{T}_{\mathrm{C} 2}$. As expected the minor content of crystalline LP phase has been observed (reaction 12) in the glass ceramics containing $\mathrm{P}_{2} \mathrm{O}_{5} \geq 1 \mathrm{~mol} \%$ as the addition of $\mathrm{P}_{2} \mathrm{O}_{5}$ is small (up to $2 \mathrm{~mol} \%$ ) [20]. This results into $\mathrm{LS}_{2}$ as main phase along with LP as minor phase in the glass ceramics with $\mathrm{P}_{2} \mathrm{O}_{5} \geq 1 \mathrm{~mol} \%$.

$$
\mathrm{P}_{2} \mathrm{O}_{5} \text { (glass) }+3 \mathrm{Li}_{2} \mathrm{O} \text { (glass) } \rightarrow 2 \mathrm{Li}_{3} \mathrm{PO}_{4} \text { ( crystal) }
$$

\subsection{Microhardness and fracture toughness}

The variation of microhardness, percentage $\mathrm{LS}_{2}$ phase and total percentage crystallinity, fracture toughness with mol \% $\mathrm{P}_{2} \mathrm{O}_{5}$ of the glass ceramics have been shown in Fig. 5 (a) and 5(b)

respectively. Mechanical properties of glass ceramics depend upon phases developed, \% crystallinity and their microstructure [21]. The phases developed, \% crystallinity, Vicker's 
microhardness, knoop hardness, modulus of elasticity and fracture toughness of all the glass ceramics are given in Table 5. The glass ceramics containing $\mathrm{P}_{2} \mathrm{O}_{5} \leq 0.5 \mathrm{~mol} \%$ possess higher crystallinity and larger crystals [22]. Since GC-1 (glass ceramic without $\mathrm{P}_{2} \mathrm{O}_{5}$ content) and GC-2 ( glass ceramic with 0.5 mol \% $\mathrm{P}_{2} \mathrm{O}_{5}$ ) possess mainly LS phase and $\mathrm{LS}_{2}$ phase could not grow sufficiently, these glass ceramics exhibit lower microhardness (5.35-5.83 GPa) compared to the glass ceramics containing $\mathrm{P}_{2} \mathrm{O}_{5} \geq 1 \mathrm{~mol} \%$ as the LS phase is less hard compared to $\mathrm{LS}_{2}$ phase $[1,23]$. The glass ceramics possessing lack nucleating agents exhibits limited number of nuclei. These limited numbers of nuclei have no restriction on their crystal growth by their neighbor nuclei as a result larger size crystals grow in these glass ceramics [24]. These larger size crystals possess larger free volume so that these crystals could easily displace when an external load is applied. As a result the glass ceramics possessing larger crystals (GC-1 and GC-2) exhibits lower microhardness [25]. The glass ceramics containing $\mathrm{P}_{2} \mathrm{O}_{5} \geq 1 \mathrm{~mol} \%$ possess higher microhardness (6.71-6.82 GPa). Higher microhardness for the glass ceramics with $\mathrm{P}_{2} \mathrm{O}_{5} \geq 1 \mathrm{~mol}$ $\%$ can also be attributed to presence of $\mathrm{LS}_{2}$ nano crystals [1] as observed from FESEM and HAADF images which has been discussed in section 3.5. The presence of nano crystals resist to relax their internal stress developed when an external load is applied. This gives higher microhardness for the glass ceramics with $\mathrm{P}_{2} \mathrm{O}_{5} \geq 1 \mathrm{~mol} \%$. Fracture toughness of glass ceramics with $\mathrm{P}_{2} \mathrm{O}_{5} \leq 0.5 \mathrm{~mol} \%$ could not be measured as they do not show proper cracks, while the glass ceramic containing $1 \mathrm{~mol} \% \mathrm{P}_{2} \mathrm{O}_{5}$ exhibits high fracture toughness $(1.36 \pm 0.04 \mathrm{Mpa} \sqrt{\mathrm{m}})$ which is shown in Fig. 5 (b). This can be attributed to the presence of rod shaped $\mathrm{LS}_{2}$ nano crystals which can hinder the crack propagation [26]. To illustrate the improper and proper cracks, the indentation marks corresponding to GC-1 and GC-3 have been shown supplementary files S2 and S3 respectively. The glass ceramics with 1.5 and 2 mol $\% \mathrm{P}_{2} \mathrm{O}_{5}$ exhibit slight lower values of the fracture toughness $(1.12 \pm 0.05$ and $1.02 \pm 0.06 \mathrm{MPa} \sqrt{\mathrm{m}}$ respectively) compared to the glass ceramic containing $1 \mathrm{~mol} \% \mathrm{P}_{2} \mathrm{O}_{5}$ which may be due to the decrease in percentage crystallinity and the absence of rod shaped crystals as well. Therefore, it has been concluded that $\mathrm{P}_{2} \mathrm{O}_{5}$ addition reduces total crystallinity, crystal growth and increases the microhardness $\left(\mathrm{H}_{\mathrm{v}}\right)$ and fracture toughness $\left(\mathrm{K}_{\mathrm{IC}}\right)$ which can be attributed to the development of nano $\mathrm{Li}_{2} \mathrm{Si}_{2} \mathrm{O}_{5}$ crystals 

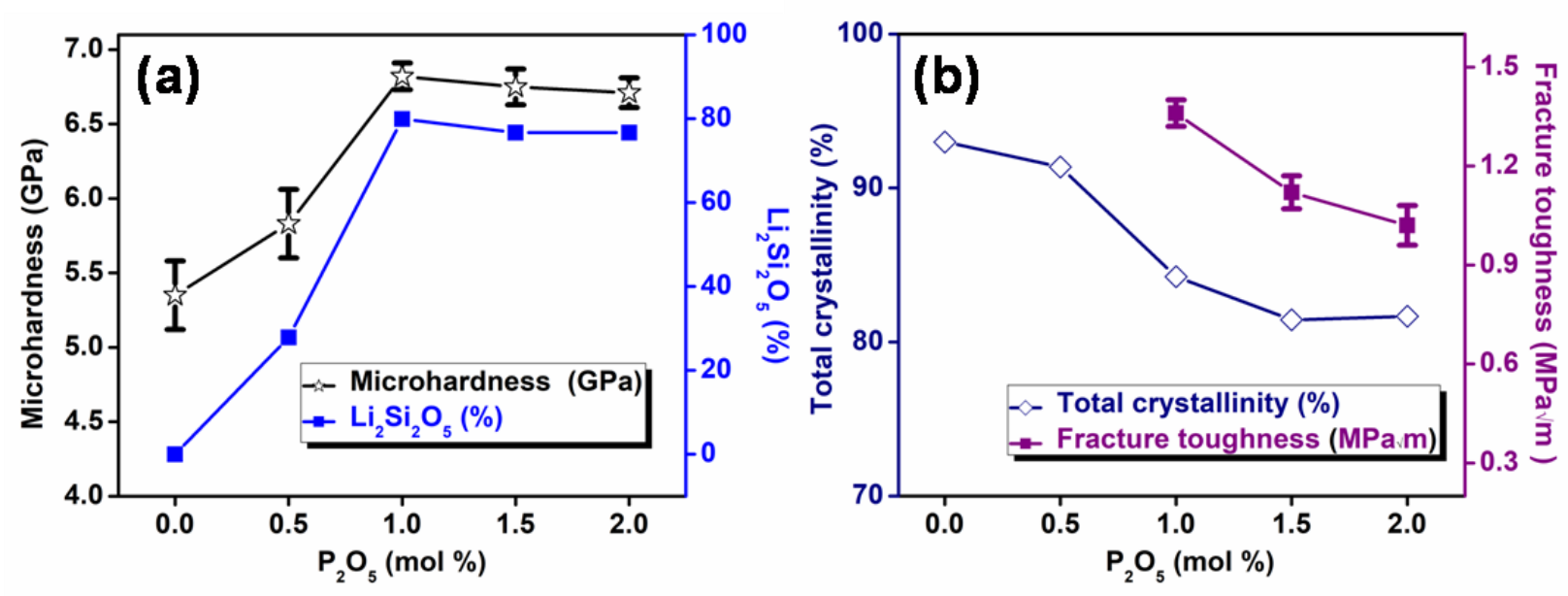

Fig. 5 (a) Variation of microhardness and $\% \mathrm{Li}_{2} \mathrm{Si}_{2} \mathrm{O}_{5}$ phase with $\mathrm{P}_{2} \mathrm{O}_{5}$ and (b) Variation of total percentage crystallinity and fracture toughness of glass ceramics with $\mathrm{P}_{2} \mathrm{O}_{5}$.

Table 5. Phases developed, \% crystallinity, microhardness, knoop hardness, Elastic modulus and fracture toughness of glass ceramics.

\begin{tabular}{|c|c|c|c|c|c|c|}
\hline $\begin{array}{c}\text { Glass } \\
\text { ceramic }\end{array}$ & $\begin{array}{c}\text { Phases } \\
\text { developed } \\
\text { (\% } \\
\text { Crystallinity) }\end{array}$ & $\begin{array}{c}\text { Total \% } \\
\text { Crystallinity }\end{array}$ & $\left(\mathrm{H}_{v \pm} \mathrm{SD}\right) \mathrm{GPa}$ & $\left(\mathrm{H}_{\mathrm{k} \pm} \mathrm{SD}\right) \mathrm{GPa}$ & $\left(E_{ \pm} \mathrm{SD}\right) \mathrm{GPa}$ & $\begin{array}{l}\text { FT } \pm \text { SD) } \\
\text { MPa } \sqrt{ } \text { m }\end{array}$ \\
\hline GC-1 & $\begin{array}{c}\mathrm{LS}(80.65) \\
\mathrm{LiAlSiO}_{4} \\
(12.34)\end{array}$ & 92.99 & $5.35 \pm 0.23$ & $4.53 \pm 0.15$ & $69.38 \pm 11.42$ & ----- \\
\hline GC-2 & $\begin{array}{c}\mathrm{LS}(46.23), \\
\mathrm{LS}_{2}(27.82) \\
\text { and } \mathrm{SiO}_{2} \\
(17.32)\end{array}$ & 91.37 & $5.83 \pm 0.23$ & $5.83 \pm 0.25$ & $78.55 \pm 12.72$ & ----- \\
\hline GC-3 & $\begin{array}{c}\mathrm{LP}(4.33) \text { and } \\
\mathrm{LS}_{2}(79.91)\end{array}$ & 84.24 & $6.82 \pm 0.09$ & $5.93 \pm 0.25$ & $106.33 \pm 11.09$ & $1.36 \pm 0.04$ \\
\hline GC-4 & $\begin{array}{c}\mathrm{LP}(4.77) \text { and } \\
\mathrm{LS}_{2}(76.66)\end{array}$ & 81.436 & $6.75 \pm 0.12$ & $5.91 \pm 0.15$ & $98.77 \pm 9.10$ & $1.12 \pm 0.05$ \\
\hline GC-5 & $\begin{array}{l}\mathrm{LP}(5) \text { and } \\
\mathrm{LS}_{2}(76.67)\end{array}$ & 81.67 & $6.71 \pm 0.10$ & $5.83 \pm 0.08$ & $91.10 \pm 3.406$ & $1.02 \pm 0.06$ \\
\hline
\end{tabular}

\subsection{FTIR and Raman spectroscopy}

Fig 6 (a) shows the IR spectra recorded on the glass powder samples. Due to the amorphous nature and wide range distribution of $Q^{k}$ species (where, $Q^{k}$ represents Silica 
tetrahedra with $k$ - bridging oxygens, where $k$ varies from 0,1,2,3 and 4 ) the IR spectra of glasses have been observed to lack sharp bands and exhibited broad bands. The IR spectra show absorption bands around 532, 789, 932, 1024 and $1184 \mathrm{~cm}^{-1}$. The bands around 932 and 1024 $\mathrm{cm}^{-1}$ are the most intense absorption bands. The assignment of IR bands has been given in Table 6. The IR band near $532 \mathrm{~cm}^{-1}$ can be attributed to the O-Si-O or Si-O-Si deformation vibrations [27]. The band at $789 \mathrm{~cm}^{-1}$ can be assigned to the bending mode of Si-O-Si group [28,29]. The intense band in the range $800-1200 \mathrm{~cm}^{-1}$ corresponds to stretching vibrations of $\mathrm{SiO}_{4}$ tetrahedron with different number of bridging oxygen atoms. The band at $932 \mathrm{~cm}^{-1}$ can be accredited to stretching vibrations of $\mathrm{Si}^{-} \mathrm{O}^{-}$[27], the band at $1024 \mathrm{~cm}^{-1}$ corresponds to Si-O-Si anti symmetric stretching of bridging oxygens within tetrahedral [30]. The band at $1184 \mathrm{~cm}^{-1}$ can be attributed to asymmetric vibrations of Si-O-Si [27]. No major changes have been observed in the FTIR spectra of the glasses as the content of $\mathrm{P}_{2} \mathrm{O}_{5}$ is small (up to $2 \mathrm{~mol} \%$ ). There is small decrease in intensity of the band at $932 \mathrm{~cm}^{-1}$ which indicates that $\mathrm{P}_{2} \mathrm{O}_{5}$ might possibly acts as glass former.
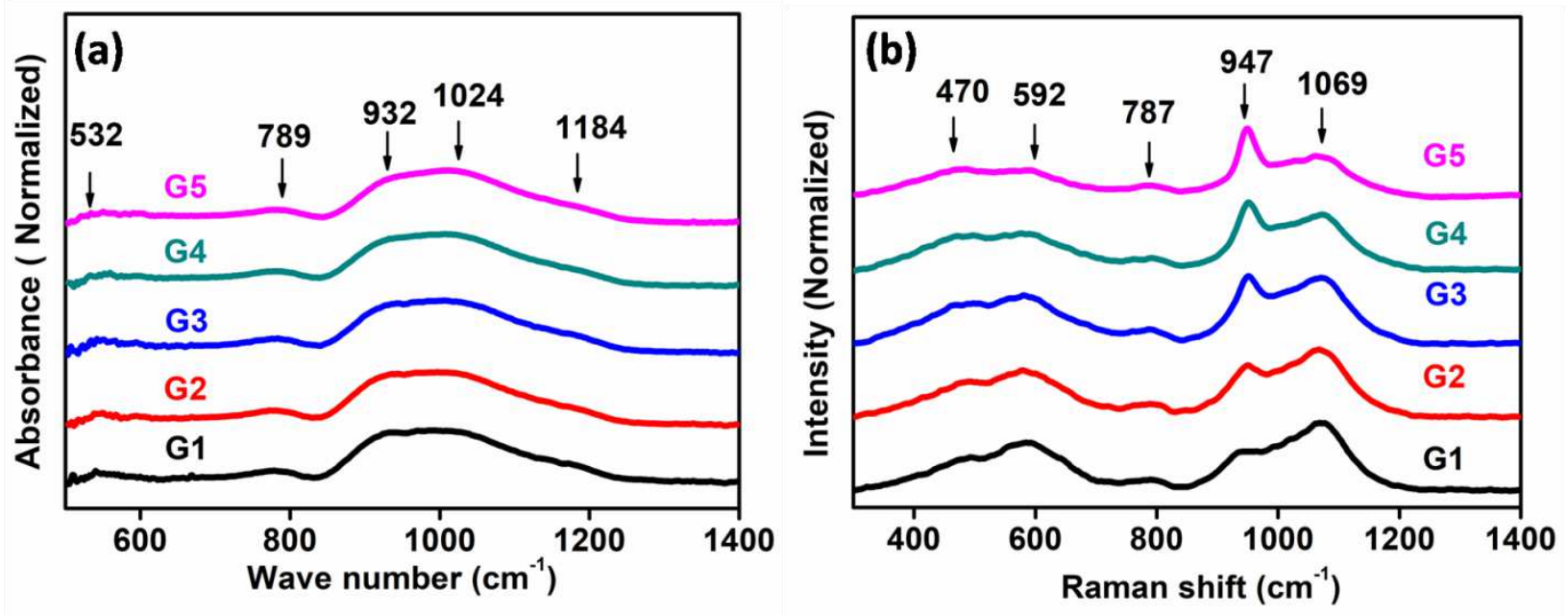

Fig. 6. (a) IR spectra of glasses and (b) Raman spectra of glasses containing 0-2 mol \% $\mathrm{P}_{2} \mathrm{O}_{5}$.

Table 6. IR peaks of all glasses and their bands assignment.

\begin{tabular}{ccc}
\hline Wave number $\left(\mathbf{c m}^{-1}\right)$ & Assignment & References \\
\hline $\mathbf{5 3 2}$ & O-Si-O or Si-O-Si & {$[27]$} \\
$\mathbf{7 8 9}$ & bending mode of Si-O-Si & {$[28,29]$} \\
& group & {$[27]$} \\
\hline
\end{tabular}




\section{4}

1184
$\mathrm{Si}-\mathrm{O}-\mathrm{Si}$ anti symmetric

stretching of bridging oxygens

asymmetric vibrations of $\mathrm{Si}$ -
[30]

\section{$\mathrm{O}-\mathrm{Si}$}

The Raman spectra for glasses possess two regions one with low frequency from 300 to $800 \mathrm{~cm}^{-1}$ and other with high frequency from 800 to $1200 \mathrm{~cm}^{-1}$ as shown in Fig. 6 (b). The Raman spectra observed for the glasses can be described by $\mathrm{Q}^{4}\left(\mathrm{SiO}_{2}\right), \mathrm{Q}^{3}\left(\mathrm{Si}_{2} \mathrm{O}_{5}\right)$ and $\mathrm{Q}^{2}\left(\mathrm{SiO}_{3}\right)$ species. The Raman spectra show bands at 470, 592, 787, 947, $1069 \mathrm{~cm}^{-1}$ respectively. The assignments of Raman bands have been given in Table 7. The band at $470 \mathrm{~cm}^{-1}$ can be attributed to the $\mathrm{Q}^{4}$ unit [31,32] . The band at $592 \mathrm{~cm}^{-1}$ corresponds to symmetrical valance vibrations $\mathrm{Q}^{2}$ ( $\mathrm{Si}-\mathrm{O}-\mathrm{Si}$ ) [31]. The band at $787 \mathrm{~cm}^{-1}$ is due to $\mathrm{Si}$ motion in oxygen cage [31]. The band around $947 \mathrm{~cm}^{-1}$ corresponds to $\mathrm{Q}^{2}$ units as well as the vibrations of the P-O bonds and the band centered around $1069 \mathrm{~cm}^{-1}$ corresponds to $\mathrm{Q}^{3}$ units [18,31-34]. For the glasses containing $\mathrm{P}_{2} \mathrm{O}_{5}$ $\leq 0.5 \mathrm{~mol} \%$ the band around $1069 \mathrm{~cm}^{-1}$ is dominant which indicates that all the glasses mainly consist of $\mathrm{Q}^{3}$ structural units. For the glasses containing $\mathrm{P}_{2} \mathrm{O}_{5} \geq 1 \mathrm{~mol} \%$ the intensity of bands around 470 and $947 \mathrm{~cm}^{-1}$ have been observed to increase which indicates the increase of the $\mathrm{Q}^{4}$ and $\mathrm{Q}^{2}$ units, while the intensity of the band around $1069 \mathrm{~cm}^{-1}$ decreases which indicates decrease of $\mathrm{Q}^{3}$ units respectively. The possible mechanism that occurs in the glasses with the addition of $\mathrm{P}_{2} \mathrm{O}_{5}$ may be due to the disproportionation reaction as given in reaction (13)[19].

$$
\begin{aligned}
& 2 \mathrm{Q}^{3} \text { (glass) } \leftrightarrow \mathrm{Q}^{2} \text { (glass) }+\mathrm{Q}^{4} \text { (glass) } \\
& \mathrm{Li}_{2} \mathrm{O}+\mathrm{Q}^{2} \text { (glass) } \rightarrow \mathrm{Li}_{2} \mathrm{SiO}_{3 \text { (Crystal) }}
\end{aligned}
$$

The increase in the intensity of the band at $470 \mathrm{~cm}^{-1}$ (corresponding to $\mathrm{Q}^{4}$ units) while the decrease in intensity of the band at $1069 \mathrm{~cm}^{-1}$ (corresponding to $\mathrm{Q}^{3}$ units) can be attributed to the polymerization of the glass network. This is also supported by the FTIR results and the increase in $\mathrm{T}_{\mathrm{g}}$ observed from DTA. It has been reported earlier that $\mathrm{Q}^{2}$ and $\mathrm{Q}^{3}$ units in the glasses promote crystallization of LS and $\mathrm{LS}_{2}$ phases respectively [13,31]. Although glasses containing $\mathrm{P}_{2} \mathrm{O}_{5} \leq$ 0.5 mol \% mainly possess $\mathrm{Q}^{3}$ units, the lithium disilicate phase has not been developed rather the LS phase has been observed in their corresponding glass ceramics (GC-1 and GC-2). This may be according to reaction (14) [17]. While the glasses with $\mathrm{P}_{2} \mathrm{O}_{5} \geq 1 \mathrm{~mol} \%$ show increase in $\mathrm{Q}^{2}$ 
and $\mathrm{Q}^{4}$ units and the $\mathrm{LS}_{2}$ phase could be developed in their corresponding g1ass ceramics (GC-3, GC-4 and GC-5) which may be due to provocation of nucleation effect as explained section 3.2.

Table 7. Raman bands of all glasses and their assignments

\begin{tabular}{ccc}
\hline Raman shift $\left(\mathbf{c m}^{-1}\right)$ & Assignment $\left(Q^{k}\right)$ & References \\
\hline $\mathbf{4 7 0}$ & Rocking of bridging oxygen $\left(\mathrm{Q}^{4}\right)$ & {$[31,32]$} \\
$\mathbf{5 9 2}$ & Si-O-Si stretching and/or bending $\left(\mathrm{Q}^{2}\right)$ & {$[31]$} \\
$\mathbf{7 8 7}$ & Symmetric stretching Si-O-Si $\left(\mathrm{Q}^{4}\right)$ & {$[31]$} \\
$\mathbf{9 4 7}$ & Symmetric stretching Si-O-Si $\left(\mathrm{Q}^{2}\right)$ and & {$[18,31-34]$} \\
& vibrations P-O bonds & {$[31,32,34]$} \\
\hline
\end{tabular}

\subsection{FESEM, HAADF-STEM and EDX analysis}

Fig. $7(a, b, c, d$ and $e$ ) show the FESEM images of glass ceramics containing 0, 0.5, 1, 1.5 and $2 \mathrm{~mol} \% \mathrm{P}_{2} \mathrm{O}_{5}$ respectively. From the figure it can be observed that with the addition of $\mathrm{P}_{2} \mathrm{O}_{5}$ the morphology of glass ceramics has been changed. Glass ceramics with $\mathrm{P}_{2} \mathrm{O}_{5} \leq 0.5$ mol \% (Fig. 7 (a) and 7 (b)) lack volume nucleation, larger flake like crystals corresponding to LS phase have been formed. With the addition of $\mathrm{P}_{2} \mathrm{O}_{5} \geq 1 \mathrm{~mol} \%$ (Fig. 7 (c), 7 (d) and 7 (e) respectively) nano scale $\mathrm{LS}_{2}$ crystals have been developed which may be due to heterogeneous nucleation at the interface of disordered $\mathrm{Li}_{3} \mathrm{PO}_{4}$ and glassy matrix in the glass ceramics as discussed in XRD results. The presence of more number of nuclei finds limited space between each nucleus that leads to crystal growth restriction. As a result nano size crystals have been formed. Among all the glass ceramics GC-4 (glass ceramic containing 1.5 mol \% $\mathrm{P}_{2} \mathrm{O}_{5}$ ) possesses smallest crystal size as shown in Fig. 7 (d). Thus HAADF-STEM imaging and EDX analysis have been carried out for GC-4. The HAADF-STEM image has been shown in Fig. 8 (a) and the EDX analysis carried out at the rectangular area represented on Fig. 8 (a) has been shown in Fig. 8 (b). The average particle size has been determined from Fig. 8 (a) by selecting over 50 particles using Image $\mathbf{J}$ software. The particle size distribution is shown in the inset image of Fig. 8 (a). The inset image shows the average particle size is about $16.88 \mathrm{~nm}$. The EDX analysis of the GC-4 confirms the presence of $\mathrm{Si}, \mathrm{O}, \mathrm{Zr}, \mathrm{Al}, \mathrm{K}, \mathrm{P}, \mathrm{Mg}, \mathrm{Ca}$ and $\mathrm{Ce}$. The presence of Lithium could not be detected from EDX analysis as it has weight below the detection range. The weight 
percentage of elements present has been given in Table 8. The elemental mapping of GC-4 has been shown in Fig. 9. The individual images of elemental mapping have been given in supplementary files (S4-S12).
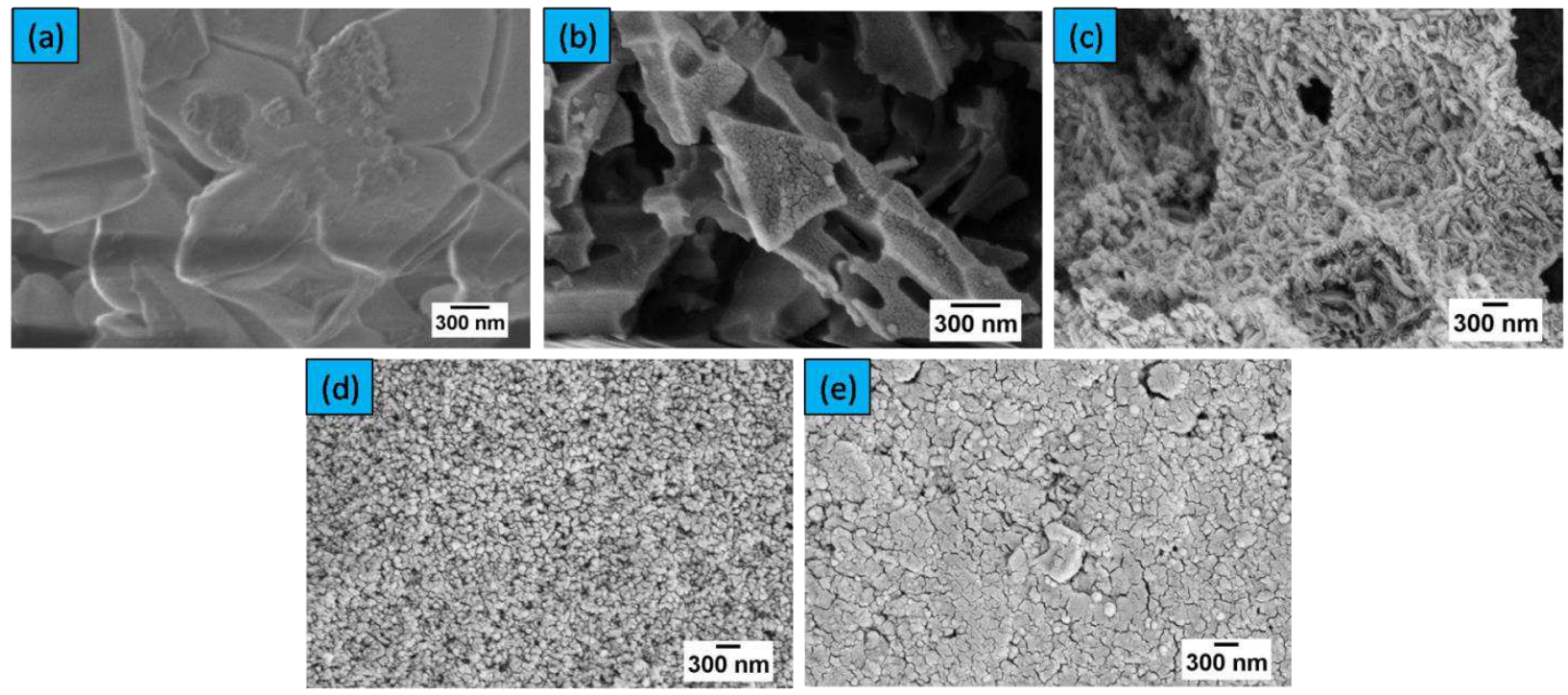

Fig.7 Glass ceramics containing : a) $0 \mathrm{~mol} \% \mathrm{P}_{2} \mathrm{O}_{5}$, b) $0.5 \mathrm{~mol} \% \mathrm{P}_{2} \mathrm{O}_{5}$, c) $1 \mathrm{~mol} \% \mathrm{P}_{2} \mathrm{O}_{5}$, d) 1.5 mol $\% \mathrm{P}_{2} \mathrm{O}_{5}$ and e) $2 \mathrm{~mol} \% \mathrm{P}_{2} \mathrm{O}_{5}$. 


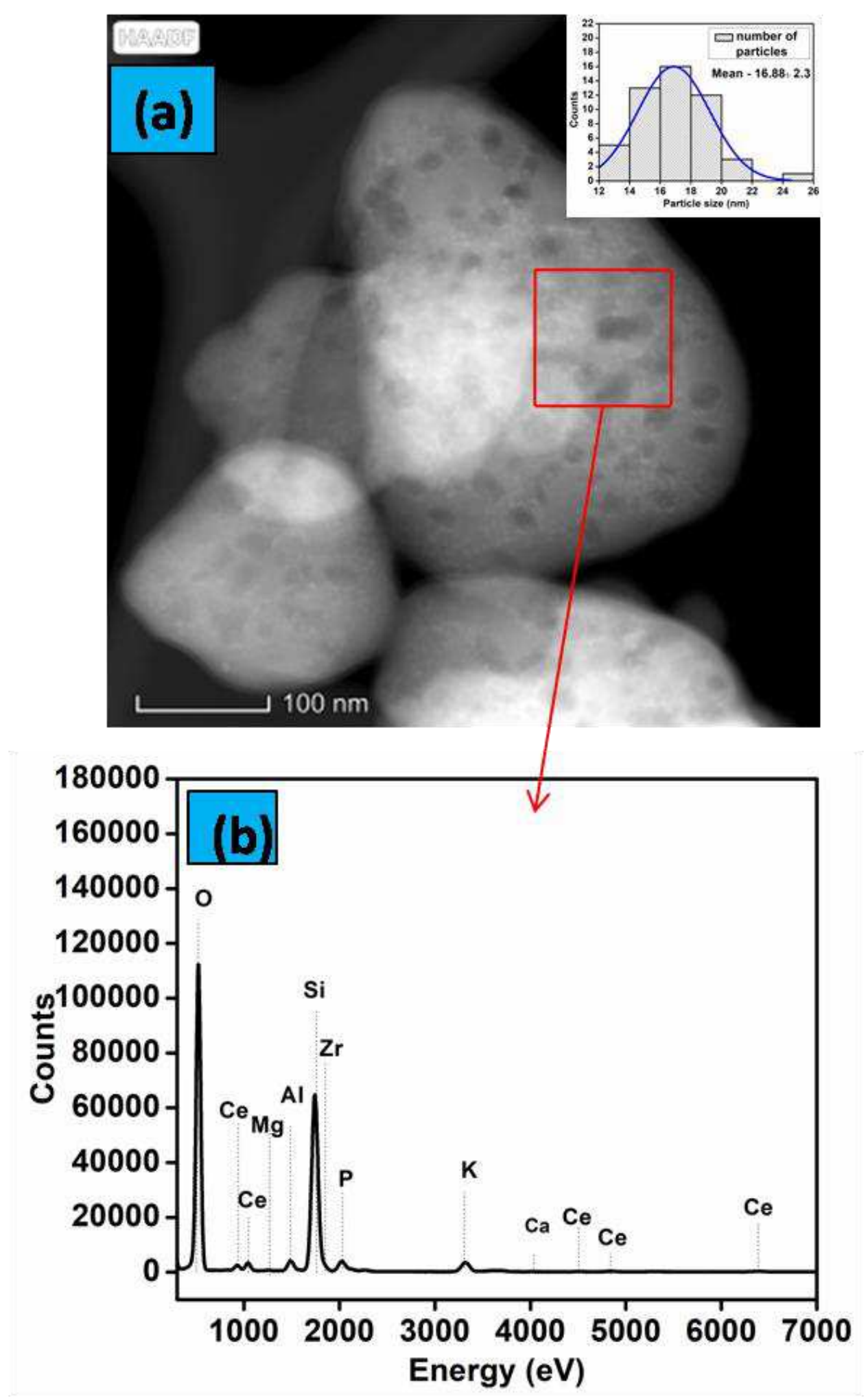

Fig. 8 (a) HAADF-STEM image of glass ceramic containing $1.5 \mathrm{~mol} \% \mathrm{P}_{2} \mathrm{O}_{5}$, the inset image shows the particle size distribution and (b) EDX analysis of glass ceramics containing $1.5 \mathrm{~mol} \%$ $\mathrm{P}_{2} \mathrm{O}_{5}$. 
Table 8. EDX analysis of glass ceramic containing $1.5 \mathrm{~mol} \% \mathrm{P}_{2} \mathrm{O}_{5}$.

\begin{tabular}{ccc}
\hline Element & Weight \% & Atomic \% \\
\hline $\mathbf{O}(\mathbf{K})$ & 52.41 & 67.72 \\
$\mathbf{S i}(\mathbf{K})$ & 36.66 & 26.98 \\
$\mathbf{A l}(\mathbf{K})$ & 1.28 & 0.98 \\
$\mathbf{Z r}(\mathbf{K})$ & 3.24 & 0.73 \\
$\mathbf{K}(\mathbf{K})$ & 4.52 & 2.39 \\
$\mathbf{P}(\mathbf{K})$ & 1.38 & 0.92 \\
$\mathbf{M g}(\mathbf{K})$ & 0.02 & 0.02 \\
$\mathbf{C a}(\mathbf{K})$ & 0.45 & 0.23 \\
$\mathbf{C e}(\mathbf{K})$ & 0.04 & 0.03 \\
\hline Totals & 100 & 100 \\
\hline
\end{tabular}




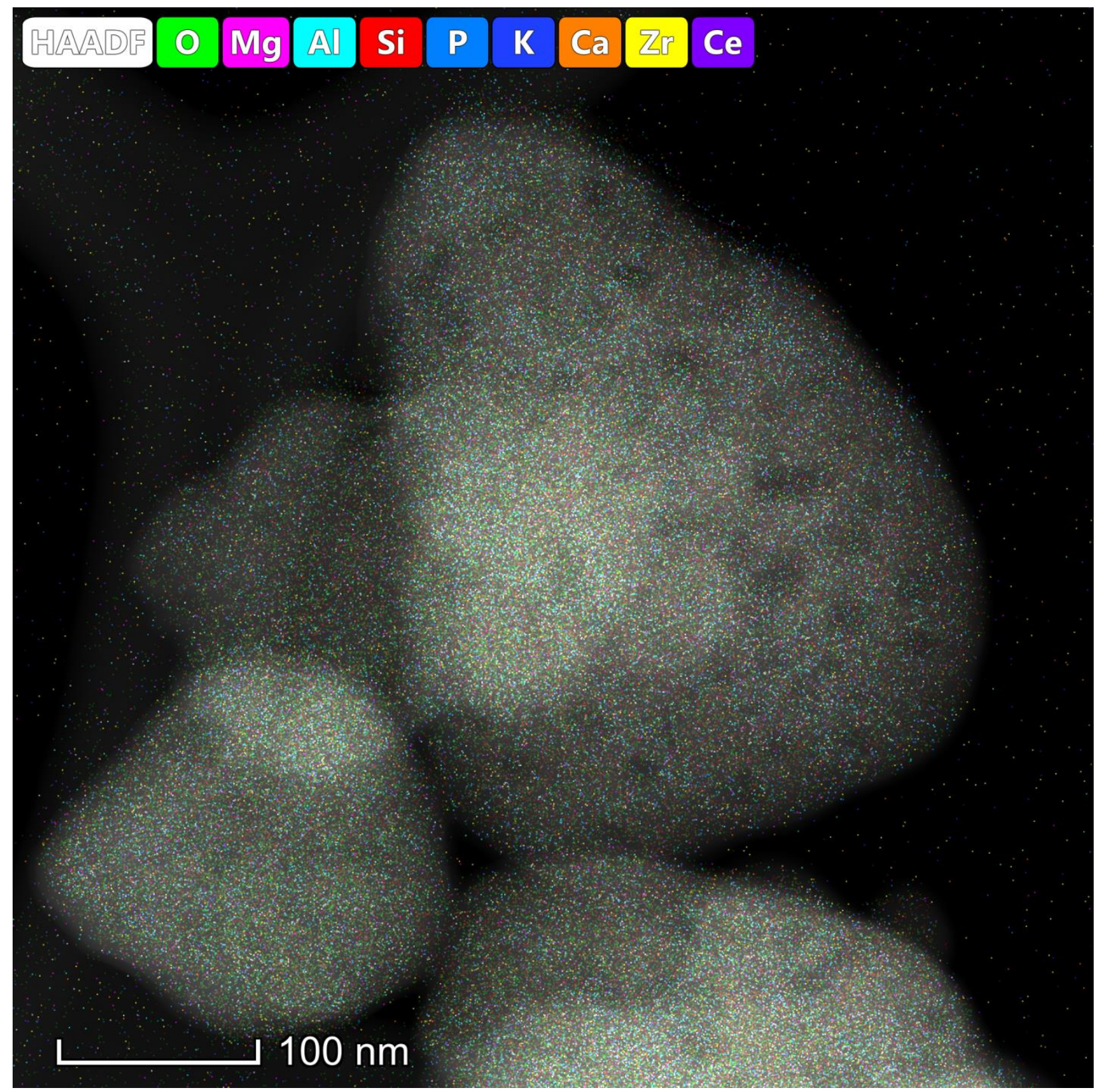

Fig. 9. HAADF Elemental mapping of glass ceramic containing $1.5 \mathrm{~mol} \% \mathrm{P}_{2} \mathrm{O}_{5}$.

\subsection{UV-Visible Transmittance spectroscopy}

Fig. 10 (a) shows UV-visible transmission spectra for all the glass ceramics. The transmission spectra of glass ceramic GC-2 overlaps on transmission spectra of GC-1. Among all the glass ceramics GC-4 shows highest transmittance in visible wavelength range. 

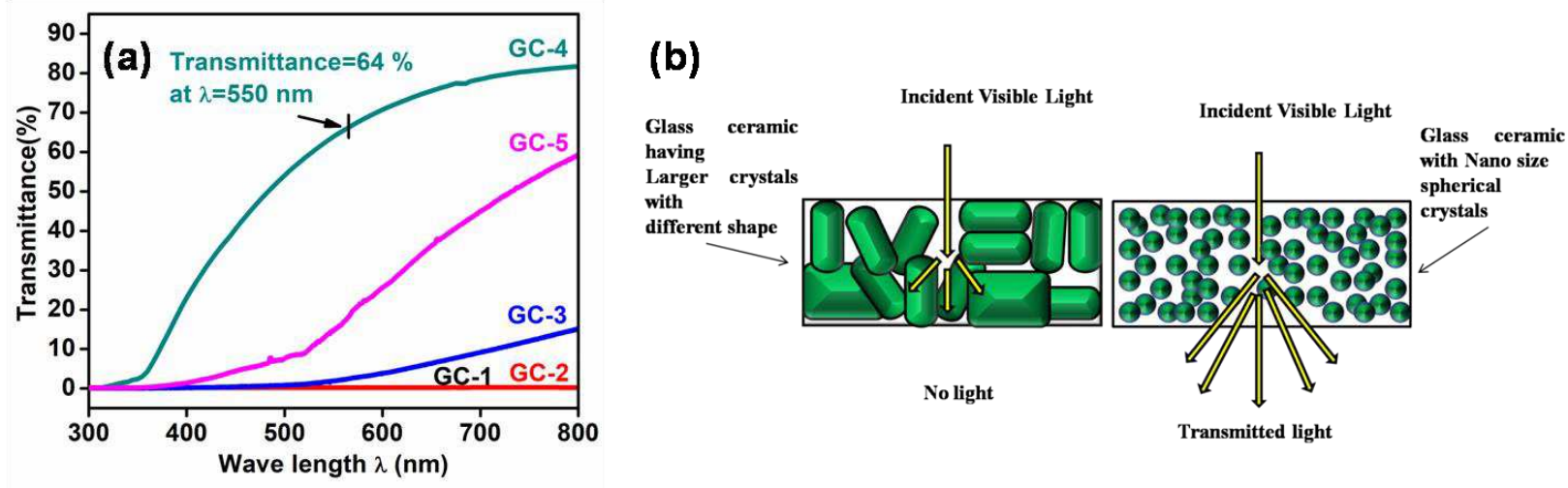

Fig. 10: (a) UV Visible spectra of the glass ceramics containing 0-2 mol \% $\mathrm{P}_{2} \mathrm{O}_{5}$ and (b)

Schematic representation of the light transmission through glass ceramics.

Transmittance of visible light in glass ceramics depends mainly on crystal size, crystallinity and refractive index of the phases present. It is well known that if the size of the crystals matches with the wavelength of light incident, greatest scattering takes place [35]. Glass ceramics with $\mathrm{P}_{2} \mathrm{O}_{5} \leq 0.5 \mathrm{~mol} \%$ possess higher crystallinity and larger crystal size as can be observed from XRD and SEM (Fig. 7(a) and 7(b)) respectively. As a result scattering of visible light takes place on the larger crystals and transparency could not be observed. From Fig. 10 (a) it can be observed that the transmittance of glass ceramics with $\mathrm{P}_{2} \mathrm{O}_{5} \geq 1 \mathrm{~mol} \%$ has increased and the glass ceramic GC-4 shows highest transmittance that is $64 \%$ at wavelength $\lambda=550 \mathrm{~nm}$ ( $\lambda=550 \mathrm{~nm}$ has been taken since human eye is more sensitive at this wavelength). For higher transparency the difference between the refractive index of glass matrix and crystals present should be less. The refractive index of $\mathrm{LS}_{2}$ phase is 1.55 which is closer to that of glass matrix 1.50 as a result transmittance of glass ceramic at visible wavelength increases [36]. The schematic representation of light transmission through glass ceramics has been shown in Fig. 10 (b). The development of $\mathrm{LS}_{2}$ phase in the glass ceramics with $\mathrm{P}_{2} \mathrm{O}_{5} \geq 1$ mol \% has been confirmed from XRD. From HAADF analysis it has been observed that the glass ceramic GC-4 has lowest $\mathrm{LS}_{2}$ crystal size (around $16.88 \mathrm{~nm}$ ). Thus presence of $\mathrm{LS}_{2}$ crystals with smallest crystal size in the glass ceramic GC-4 causes highest transmittance among all the glass ceramics. Hence, the addition of $\mathrm{P}_{2} \mathrm{O}_{5}$ to $\mathrm{LS}_{2}$ based glass ceramics increases both the transparency and microhardness which are of great importance for several applications such as armors and aesthetics in dentistry. 


\section{Conclusions}

Addition of $\mathrm{P}_{2} \mathrm{O}_{5}$ reduces the overall percentage of crystallinity, crystal size but it facilitates lithium disilicate phase formation and improves microhardness. The glass ceramics with $\mathrm{P}_{2} \mathrm{O}_{5} \geq 1 \mathrm{~mol} \%$ have high microhardness (6.71-6.82 GPa) and moderate fracture toughness (1.02-1.36 $\mathrm{MPa} \sqrt{\mathrm{m}})$ among all the glass ceramics. Glass ceramic containing $1.5 \mathrm{~mol} \% \mathrm{P}_{2} \mathrm{O}_{5}$ exhibits nano crystals of size $16.88 \mathrm{~nm}$ and showed improved transparency at the wave length $550 \mathrm{~nm}$. A good correlation is observed between crystallinity, microstructure and microhardness

of these glass ceramics. These Lithium disilicate glass ceramics with improved mechanical and optical properties have great potential in dental and armor applications.

\section{Acknowledgements:}

The authors wish to thank Prof. V.K. Deshpande for providing laboratory facilities and DRDO for providing grant to support this research.

Funding: This work was supported by the Defence Research and Development Organization (DRDO) India (Grant no. ARMREB/MAA/2016/187).

Conflict of interest: The authors declare that they have no known competing financial interests or personal relationships that could have appeared to influence the work reported in this paper.

\section{Ethics approval:}

The authors declare that the work is original and the manuscript has been not submitted to any other journals and it has not been published elsewhere. The authors also declare that the results presented in this manuscript are clear, not fabricated or falsified inappropriate data and proper acknowledgements has been given to the other works that could help to explain the science in the form of references.

Consent to participate: Not applicable

Consent for publication: Not applicable

Availability of data and materials: Not applicable

\section{Authors' contributions:}

Conceptualization: [Anuradha Vilas Deshpande and Peddy Satyanarayana]

Scrub the data and maintain the research data where it is necessary:

[Anuradha Vilas Deshpande and Peddy Satyanarayana] 
Application of statistical, mathematical, computational, or other formal techniques to analyze

or synthesize study data: [Anuradha Vilas Deshpande and Peddy Satyanarayana]

Supervision: [Anuradha Vilas Deshpande]

Writing - original draft: [Peddy Satyanarayana]

Writing - review \& editing: [Anuradha Vilas Deshpande]

\section{References:}

[1] S. Huang, P. Cao, C. Wang, Z. Huang, W. Gao, Fabrication of a high-strength lithium disilicate glass-ceramic in a complex glass system, J. Asian Ceram. Soc. 1 (2013) 46-52. doi:10.1016/j.jascer.2013.02.007.

[2] Z. Khalkhali, B. Eftekhari Yekta, V.K. Marghussian, Mechanical and chemical properties of $\mathrm{Zr}$ and P-doped lithium disilicate glass ceramics in dental restorations, Int. J. Appl. Ceram. Technol. 9 (2012) 497-506. doi:10.1111/j.1744-7402.2011.02661.x.

[3] A. Gaddam, H.R. Fernandes, D.U. Tulyaganov, M.J. Ribeiro, The roles of P 205 and $\mathrm{SiO} 2 / \mathrm{Li} 2 \mathrm{O}$ ratio on the network structure and crystallization kinetics of nonstoichiometric lithium disilicate based glasses, J. Non. Cryst. Solids. 481 (2018) 512-521. doi:10.1016/j.jnoncrysol.2017.11.034.

[4] K. Yuan, F. Wang, J. Gao, X. Sun, Z. Deng, H. Wang, J. Chen, Effect of sintering time on the microstructure, flexural strength and translucency of lithium disilicate glass-ceramics, J. Non. Cryst. Solids. 362 (2013) 7-13. doi:10.1016/j.jnoncrysol.2012.11.010.

[5] W. Höland, E. Apel, C. van 't Hoen, V. Rheinberger, Studies of crystal phase formations in high-strength lithium disilicate glass-ceramics, J. Non. Cryst. Solids. 352 (2006) 40414050. doi:10.1016/j.jnoncrysol.2006.06.039.

[6] Y. Bai, L. Peng, Q. Zhu, The preparation of the lithium disilicate glass-ceramic with high translucency, J. Non. Cryst. Solids. 457 (2017) 129-134. doi:10.1016/j.jnoncrysol.2016.11.032.

[7] S. Barone, A. Freulon, B. Malard, M. Dehmas, Solid-state phase transformation in a lithium disilicate-based glass-ceramic, J. Non. Cryst. Solids. 513 (2019) 9-14. doi:10.1016/j.jnoncrysol.2019.03.006.

[8] F. Wang, J. Gao, H. Wang, J. hua Chen, Flexural strength and translucent characteristics of lithium disilicate glass-ceramics with different P2O5 content, Mater. Des. 31 (2010) 3270-3274. doi:10.1016/j.matdes.2010.02.013.

[9] Mimi Hayati Abdul Rahaman;Mayeen Uddin Khandaker; Ziaul Raza Khan; Mohd Zieauddin Kufian; Ikhwan Syafiq Mohd Noor; and Abdul Kariem Arof., Effect of gamma irradiation on poly(vinyledene difluoride)-lithium bis(oxalato)borate electrolyte, Phys.Chem.Chem.Phys. 16 (2014) 11527-11537. doi:10.1039/c4cp01233j.

[10] S. Huang, B. Zhang, Z. Huang, Crystalline phase formation , microstructure and mechanical properties of a lithium disilicate glass - ceramic, J. Mater. Sci. 48 (2013) 251257. doi:10.1007/s10853-012-6738-y.

[11] Manlika Kamnoy; Kamonpan Pengpat; Uraiwan Intatha; Sukum Eitssayeam., Effects of heat treatment temperature on microstructure and mechanical properties of lithium disilicate-based glass-ceramics, Ceram. Int. 44 (2018) S121-S124.

doi:10.1016/j.ceramint.2018.08.223. 
[12] R.S. Soares; R.C.C. Monteiron;M.M.R.A. Lima; R.J.C. Silva., Crystallization of lithium disilicate-based multicomponent glasses - effect of silica / lithia ratio, Ceram. Int. 41 (2015) 317-324. doi:10.1016/j.ceramint.2014.08.074.

[13] J. A. AUGIS ; J. E. BENNETT., CALCULATION OF THE AVRAMI PARAMETERS FOR HETEROGENEOUS SOLID STATE REACTIONS USING A MODIFICATION OF THE KISSINGER METHOD, J. Therm. Anal. Vol. 13 (1978) 283-292. doi:10.1007/BF01912301.

[14] Z. Shan, J. Liu, F. Shi, S. Liu, L. Yu, C. Wu, C. Wang, A new strengthening theory for improving the fracture strength of lithium disilicate glass-ceramics by introducing $\mathrm{Rb}$ or Cs ions, J. Non. Cryst. Solids. 481 (2018) 479-485. doi:10.1016/j.jnoncrysol.2017.11.038.

[15] Shiv Prakash Singh; Alisson Mendes Rodrigues; Heloisa Daltoso Orsolini; Paulo Parreira Gomes de Mattos;Edgar Dutra Zanotto;Jean, Patricia; Bénard-Rocherullé;

RonanLebullenger., Crystallization pathways and some properties of lithium disilicate oxynitride glasses, Ceram. Int. 43 (2017) 2348-12356.

doi:10.1016/j.ceramint.2017.06.100.

[16] Sudha MAHADEVAN, A.GIRIDHAR and A.K.SINGH, Calorimetric measurements, 88 (1986) 11-34. doi:10.1016/S0022-3093(86)80084-9.

[17] C. dos S. Bruno Galvão Simba; Marcos Valério Ribeiro; Paulo A. Suzuki; Manuel Fellipe R.P. Alves; Kurt Strecker, Mechanical properties of lithium metasilicate after short-term thermal treatments, J. Mech. Behav. Biomed. Mater. 98 (2019) 179-186. doi:10.1016/j.jmbbm.2019.06.011.

[18] P. Glatz, M. Comte, L. Cormier, L. Montagne, B. Doumert, G.G. Moore, Di ff erent roles of phosphorus in the nucleation of lithium aluminosilicate glasses, J. Non. Cryst. Solids. 493 (2018) 48-56. doi:10.1016/j.jnoncrysol.2018.04.021.

[19] C. Bischoff, H. Eckert, E. Apel, V.M. Rheinberger, W. Höland, Phase evolution in lithium disilicate glass-ceramics based on non-stoichiometric compositions of a multi-component system: Structural studies by29Si single and double resonance solid state NMR, Phys.

Chem. Chem. Phys. 13 (2011) 4540-4551. doi:10.1039/c0cp01440k.

[20] G. Wen, X. Zheng, L. Song, Effects of P 2 O 5 and sintering temperature on microstructure and mechanical properties of lithium disilicate glass-ceramics, Acta Mater. 55 (2007) 3583-3591. doi:10.1016/j.actamat.2007.02.009.

[21] S.M. Salman, S.N. Salama, E.A. Mahdy, Crystallization characteristics and properties of lithium germanosilicate glass-ceramics doped with some rare earth oxides, S.M.Salman;S.N.Salama;Ebrahim A.Mahdy. 58 (2019) 94-102. doi:10.1016/j.bsecv.2018.08.001.

[22] Mariana O. C. Villas-Boas;Francisco C. Serbena;Viviane O. Soares;Ivan Mathias;Edgar D. Zanotto., Residual Stress Effect on the Fracture Toughness of Lithium Disilicate GlassCeramics, J. Am. Ceram. Soc. 103 (2019) 465-479. doi:10.1111/jace.16664.

[23] A. Nemati, P. Goharian, M. Shabanian, A. Afshar, Effects of nucleation agent particle size on properties , crystallisation and microstructure of glass - ceramics in $\mathrm{TiO} 2-\mathrm{ZrO} 2-\mathrm{Li}$ $2 \mathrm{O}-\mathrm{CaO}-\mathrm{Al} 2 \mathrm{O} 3$ - $\mathrm{SiO} 2$ system, 109 (2010) 318-324. doi:10.1179/174367609X422063.

[24] Ting Zhao; Mei-Mei Lian; Yi Qin; Jian-Feng Zhu; Xin-Gang Kong \& Jian-Feng Yang., Improved performances of lithium disilicate glass- ceramics by seeds induced crystallization, J. Adv. Ceram. 10 (2021) 614-626. doi:10.21203/rs.3.rs-48775/v1.

[25] H.D. M. M. Gomaa, H. A. Abo-Mosallam, Electrical and mechanical properties of alkali 
barium titanium alumino borosilicate glass-ceramics containing strontium or magnesium Electrical and mechanical properties of alkali barium titanium alumino borosilicate glassceramics containing strontium or, J Mater Sci Mater Electron. 20 (2009) 507-516. doi:10.1007/s10854-008-9758-2.

[26] Manuel Fellipe Rodrigues Pais Alves; Bruno Galvão Simba; Leonardo Queiroz Bueno de Campos; Iago Ferreira; Claudinei dosSantos., Influence of heat-treatment protocols on mechanical behaviour of lithium silicate dental ceramics, Int. J. Appl. Ceram. Technol. 16 (2019) 1920-1931. doi:10.1111/ijac.13257.

[27] J. Coyle, C. Apblett, M. Brumbach, J. Ohlhausen, C. Stoldt, Structural and compositional characterization of RF magnetron cosputtered lithium silicate films: From Li $2 \mathrm{Si} 2 \mathrm{O} 5$ to lithium-rich Li 8 SiO 6, J. Vac. Sci. Technol. A. 35 (2017). doi:10.1116/1.4998726.

[28] L. Tan, J.C. Mauro, J. Peng, X. Yang, M. Peng, Quantitative prediction of the structure and properties of $\mathrm{Li} 2 \mathrm{O}-\mathrm{Ta} 2 \mathrm{O} 5-\mathrm{SiO} 2$ glasses via phase diagram approach, 102 (2019) 185-194. doi:10.1111/jace.15910.

[29] F. H. ElBatal - M. A. Ouis - A. M. Abdelghany - N. A. Ghoneim., Structural and Optical Correlation of Gamma-Irradiated 3d Transition Metals-Doped Lithium Disilicate Glasses, Silicon. 7 (2015) 409-417. doi:10.1007/s12633-014-9274-3.

[30] J. Shi, F. He, J. Xie, H. Yang, Z. Guo, X. Liu, Exploring the in fl uences of Li 2 O / SiO 2 ratio on $\mathrm{Li} 2 \mathrm{O}-\mathrm{Al} 2 \mathrm{O} 3-\mathrm{SiO} 2-\mathrm{B} 2 \mathrm{O} 3-\mathrm{BaO}$ glass-ceramic bonds for vitri fi ed cBN abrasives, 45 (2019) 15358-15365. doi:10.1016/j.ceramint.2019.05.029.

[31] Morsi M. Mahmoud; Diane C. Folz; Carlos T. A. Suchicital; and David E. Clark., Crystallization of Lithium Disilicate Glass Using Microwave Processing*, 585 (2012) 579-585. doi:10.1111/j.1551-2916.2011.04936.x.

[32] T. Fuss, A. Moguš-Milanković, C.S. Ray, C.E. Lesher, R. Youngman, D.E. Day, Ex situ XRD, TEM, IR, Raman and NMR spectroscopy of crystallization of lithium disilicate glass at high pressure, J. Non. Cryst. Solids. 352 (2006) 4101-4111. doi:10.1016/j.jnoncrysol.2006.06.038.

[33] F. Lodesani, M.C. Menziani, K. Maeda, Y. Takato, S. Urata, A. Pedone, Disclosing crystal nucleation mechanism in lithium disilicate glass through molecular dynamics simulations and free - energy calculations, Sci. Rep. 10:17867 (2020) 1-14. doi:10.1038/s41598-020-74764-9.

[34] Manjunath T. Nayak ; J.A. Erwin Desa., Roles of iron and lithium in silicate glasses by Raman spectroscopy, 49 (2018) 1507-1513. doi:10.1002/jrs.5397.

[35] S. Hendy, Light scattering in transparent glass ceramics, Appl. Phys. Lett. 81 (2002) 1171-1173. doi:10.1063/1.1499989.

[36] P. Zhang, X. Li, J. Yang, S. Xu, Effect of heat treatment on the microstructure and properties of lithium disilicate glass-ceramics, J. Non. Cryst. Solids. 402 (2014) 101-105. doi:10.1016/j.jnoncrysol.2014.05.023. 


\section{Supplementary Files}

This is a list of supplementary files associated with this preprint. Click to download.

- S1copy.jpg

- S2copy.jpg

- S3copy.jpg

- S4copy.jpg

- S5copy.jpg

- S6copy.jpg

- S7copy.jpg

- S8copy.jpg

- S9copy.jpg

- S10copy.jpg

- S11copy.jpg

- S12copy.jpg 